\title{
An Interactive Model for Analyzing the Development of the Communication Discipline: Israel as a Case Study
}

\author{
Anat First \\ Netanya Academic College, Israel \\ Hanna Adoni \\ Interdisciplinary Center Herzliya, Hebrew University of Jerusalem, Israel
}

\begin{abstract}
Our paper presents an interactive four-dimensional model for studying the long- and short-term development of the communication discipline with Israel serving as a case study: institutional-contextual, institutional-in-field, intellectual-contextual, and intellectual-in-field. Our empirical analysis utilized personal interviews, archive documents, and statistical data. Four main processes were discerned: transition from integration to alienation between institutions of higher learning and the larger political and ideological context; a shift from Hebrew University Institute of Communication's institutional monopoly to a multiplicity of increasingly competitive communication schools/departments; transition from intellectual hegemony to limited intellectual diversity; and gradually improving status for the communication field among social science disciplines. Our case-study analysis validated the interactive relationship among the model's conceptual dimensions, calling for future cross-national comparisons.
\end{abstract}

Keywords: development of communication discipline, interactive model, conceptual dimensions, limited intellectual diversity, communication field in Israel

The retrospective, self-reflexive discourse on communication as a "field" or a "discipline" has flourished during the last decade. Our earlier research, which reflected this trend, suggested a theoretical framework based on criteria anchored in the sociology of science and then applied these criteria to an analysis of the institutionalization and development of the communication field in Israel, from its early beginnings in the 1960s, to its flourishing and consolidation in the 1990s, and up to the start of the first decade of the present century (Adoni \& First, 2006; First \& Adoni 2007). In the present paper, we continue to follow the field's development, while suggesting a conceptual model for research of communication discipline ${ }^{1}$.

In the recent empirical literature, two widely consensual statements have emerged concerning studies that focused on the development of communication as a field or discipline. First, such studies are considered fragmented and rather chaotic (Lang, 2013; Pooley \& Park, 2013; Simonson, Peck, Craig, \& Jackson, 2013); Second, scholars agree that such studies' international perspective has been almost completely neglected (Simonson \& Peters, 2008). In our opinion, these phenomena are at least partly a consequence of these studies'

\footnotetext{
1 The historical development of the Institute of Communication at the Hebrew University of Jerusalem was elaborated in detail and according to its main chronological periods, in First, A., \& Adoni, H. (forthcoming). The story of the communication field in Israel: Nation building, personal transfer and growth. Chapter 23 in. P. Simonson, \& D. W. Park (Eds.), New Histories of Communication Study. New York: Routledge, Forthcoming.
} 
sole use of a historical empirical strategy for analysis. Such a methodology tends to focus on the idiosyncrasies of each society and thereby remains mainly descriptive, with no common conceptualization to enable systematic organization or comparison to other societies. We assert that, indeed, these two concerns about the existing literature are intellectually interconnected, and we propose that an attempt to develop conceptual tools for holistic, systematic analysis of the communication discipline within one society may hopefully not only overcome the tendency toward fragmented research but also open new vistas for comparative research.

Taking into consideration the prolific professional literature published since our first study (Adoni \& First, 2006; First \& Adoni, 2007), in the present paper we shall revisit our former analysis and extend it in two distinct yet interrelated directions. First, in this paper we further develop our theoretical model, adopting recent theoretical conceptualizations; Second, we apply this model to the analysis of historical and recent changes in one nation's communication field, as a case study. Hopefully, our analysis of Israel's communication field, applying the model to one specific society, will also contribute to the much needed systematic cross-national research on this issue. In the present paper, as in our earlier research, the empirical examination of the Israeli scene was based on statistical data, personal interviews with Israeli academics, and analysis of relevant historical documents.

\section{Conceptual Research Dimensions of the Communication Field and the Interactive Model}

In our earlier studies we used four research dimensions for studying communication field (Adoni \& First, 2006): (1) societal institutions (i.e., politics, economy); (2) organizational aspects of institutions of higher learning; (3) intellectual paradigms of the field; and (4) central academic figures' functions in developing and disseminating these paradigms. In our opinion, these dimensions were conceptually close to Pooley and Park's (2013) two-by-two typology according to two pairs of criteria - an institutional/intellectual pair and a field-centric/contextual pair - where the two criteria within each pair are not mutually exclusive. In the first pair of criteria, the institutional criterion concentrates on institutional and organizational aspects of the institutions of higher learning, while the intellectual criterion accounts for the evolution of ideas and scientific trends. In the second pair, the field-centric criterion focuses on developments within the communication discipline, while the contextual criterion deals with the influences of the surrounding environment such as politics, economy, ideology, and culture as well as intellectual influence of cognate disciplines.

Pooley and Park's (2013) concise, encompassing, two-by-two typology enabled them to define four new complex dimensions, which permitted them to systematically classify various research studies on the communication discipline. We adopted these same dimensions, because on the one hand they succinctly embodied our earlier analysis and on the other hand they offer the advantage of developing a conceptual model of interaction between different dimensions of the communication discipline.

Thus, as seen in Table 1, in the four-dimensional model that we applied in the current study, the institutional-contextual dimension refers to the study of the communication discipline as part of the institutional scientific system interacting with other societal institutional systems (e.g., political or economic institutions as well as other parts of the cultural system). As in Pooley and Park's typology, in our model the institutional-in-field dimension focuses on the organization of institutions of higher learning and the interactions among them within the communication field.

The intellectual-in-field dimension deals with ideas, paradigms, and subjects of scholarly interest. In our study, we expanded this dimension to include special focus on the concept of scientific transfer of ideas through 
both organizations and prominent individual scholars. Finally, once again similarly to Pooley and Park's model, the intellectual-contextual dimension involves the relationships within the higher education field, in particular with cognate disciplines (i.e., sociology, social psychology, political science).

Taking these four dimensions one step further, we contend that this model is interactive: namely, changes in any of these four dimensions will affect the other dimensions and transform them in some way (see Figure 1). In the present paper, we demonstrate several examples of such interactions characterizing the field's development in Israel.

Table 1

Four Research Dimensions of the Communication Field

\begin{tabular}{|c|c|c|}
\hline & Field-centric & Contextual \\
\hline $\begin{array}{l}\text { Institutional/ } \\
\text { Organizational }\end{array}$ & $\begin{array}{l}\text { - University and college departments/schools } \\
\text { of communication/schools } \\
\text { journalism/speech departments } \\
\text { - Communication research institutes } \\
\text { - Patterns of interaction among the above }\end{array}$ & $\begin{array}{l}\text { National political, economic, and cultural } \\
\text { institutions } \\
\text { Media industry }\end{array}$ \\
\hline Intellectual & $\begin{array}{l}\text { - Paradigms } \\
\text { - Theories } \\
\text { - Research interests } \\
\text { - Leaders of intellectual and scientific opinion } \\
\text { - Academic drift } \\
\text { - Transmission of ideas }\end{array}$ & $\begin{array}{l}\text { - Cognate disciplines or "mother" disciplines (i.e., } \\
\text { sociology, social psychology, political science, } \\
\text { history) }\end{array}$ \\
\hline
\end{tabular}

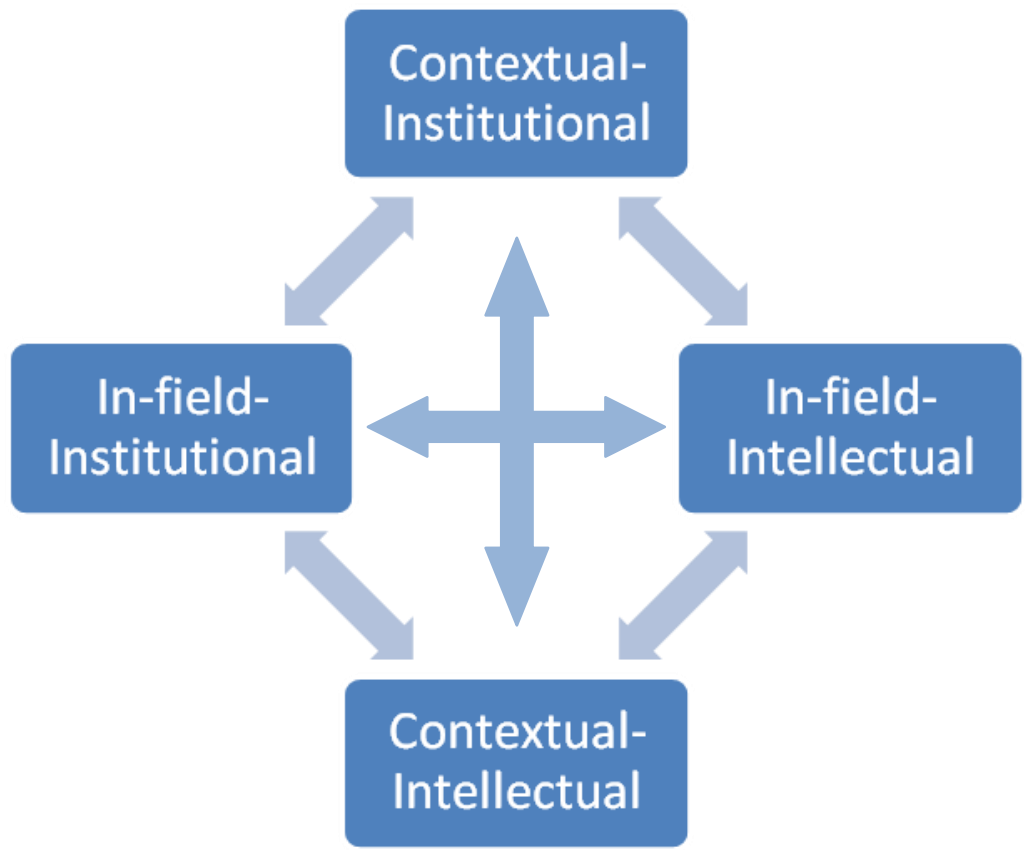

Figure 1. Interactive model of the research dimensions of the communication field.

While Pooley and Park used their typology to categorize a body of studies on communication, the currents study had three distinct yet interrelated goals: (1) to achieve a holistic perspective (rather than a fragmented one) by simultaneously applying all four dimensions of the interactive model to the case study of the development of the communication discipline in Israel; (2) to combine analytic methods by using this conceptual model alongside a historical empirical strategy for analyzing the society's unique features, thereby examining both 
long-term and short-term changes and enabling future comparison of this single society to other societies; and (3) to validate our four-dimensional model and the dimensions' proposed dynamic interdependence and interactions, to serve as the basis for formulation of research questions in the future.

In each of the following sections of this paper, we begin with a general theoretical discussion of each dimension and then apply it to the Israeli case study.

\section{The Institutional-Contextual Dimension: From Integration to Alienation}

As described above, the institutional-contextual dimension deals with patterns of interaction between the communication discipline (as a part of an institutional scientific system) within its surrounding political, cultural, and economic institutions. The transformation that occurred in the early 20th century, from Marx's materialist determinism to the Weberian emphasis on the value system, led to Merton's (1957) expansion of Weber's ideas on the relationship between science and the political system. Other social thinkers, each from their own perspective, but not yet regarding the discipline of communication specifically (Alexander, 1998; Eisenstadt, 1989; Foucault, 1969/2002; Mannheim, 1952), were interested in the relations between the ideological worldview of dominant social groups in institutional systems on the one hand and the knowledge they produce on the other hand. Ben David (1991) focused on the growth of new scientific disciplines in different European societies, assuming that autonomous science is an essential component of liberal democracy, and that the growth of science depends on competition between universities acting within a decentralized academic system (Crane, 1994; Freudenthal, 1991).

In the specific case of Israel's institutional-contextual dimension, historical research on the patterns of interaction between scientific and other societal institutions that were not necessarily in the communication field (Katz \& Hed, 1997) demonstrated that the establishment of the pioneering Hebrew University of Jerusalem (HUJ) in 1925 was part of the nation-building project aiming to create a Jewish state in Palestine. Zionist ideology influenced the development of the social sciences in general (Ram, 1994) and of the communication discipline in particular (Adoni \& First, 2006). Even before the establishment of Israel in 1948, visible close working relationships emerged between various political institutions and many of HUJ's departments, and its faculty members were openly and actively mobilized to contribute to the building of the new society.

In the Israeli communication field, these deep links were rather symbolically represented by Elihu Katz, a young social scientist who immigrated to Israel from the USA, who played simultaneous dual roles (in 1965-1967) as the academic founder of the Institute of Communication at HUJ and also as the director of Israel's newly established Israeli television. Katz, a former student of Paul Lazarsfeld at Columbia University's Bureau of Social Research, from the very beginning encouraged a close working relationship between the HUJ Institute of Communication and the Israel Institute of Applied Social Research (IASR), a non-profit public institution directed by Louis Guttman, another American social scientist. Guttman founded his Institute in 1948, the same year as Israel's statehood was established, and he conducted the IASR with the conscious intention of assisting the new society's nation-building process. Thus, Guttman's IASR studied different subjects in line with funding provided by the Israel Defense Forces (IDF), the Office of the Prime Minister, the Israeli Broadcasting Authority, the Ministry of Education and Culture, the Ministry of Health, and other government agencies, while conducting ongoing surveys of radio listening and television viewing for the Israeli Broadcasting Authority. The close ties between the IASR and governmental agencies influenced the choice of 
topics investigated not only in the IASR but also in the HUJ's Institute of Communication, with an emphasis on applied social research.

The symbiotic relations between the IASR and the Institute of Communication were seen as crucial, given their activities' perceived significant contribution to national mobilization efforts, especially during emergency periods. Almost all of the Institute of Communication's faculty members took an active part in these projects, and the research reports were published jointly by the both Institutes. Most of the questions explored concerned the actual policy of various government agencies. This type of administrative research required mostly quantitative, policy-related methods and as such constituted the cradle in which the functional theories and empiricist methodology of social and communication research crystallized as the dominant orientation of the HUJ Institute of Communication (Adoni \& First, 2006; Gratch, 1973).

Thus, the close-knit ties between the communication field and fledgling Israel's political societal institutions must be perceived against the backdrop of the reciprocal interrelations between the system of higher learning and the political ideology of the time. In fact, these interrelations bolstered the political hegemony of the long-ruling Labor Party (Mapai) over the ideological orientation in social science research (Ram, 1994), as well as in communication research ${ }^{2}$.

This symbiotic institutional-contextual situation (between political institutions and communication research organizations) typifying the pre-state era and Israel's first few decades has undergone a drastic change since the end of the 1980s. These changes coincided with general trends toward the enhancement of individualistic and neo-liberal tendencies in Israeli society and the subsequent policies of privatization that have emerged in all life domains. In our earlier research (Adoni and First, 2006), we noted several evidences of privatization in Israel's communication field. First, in the 1990s, three communication schools were established within private academic colleges, which, in contrast to universities and public colleges, are not financed by governmental budgets. Furthermore, we previously discerned an increase in private profit-oriented research agencies in the communication field like cable network research departments or private research institutes, which engage in applied social research such as public opinion studies or media ratings. This trend has intensified significantly in the last decade: Our recent findings (First \& Adoni, 2013) show about 55 private agencies currently operating in Israel that are involved in research on media consumption and public opinion. Although government bodies continue to fund some communication research projects, most communication and public opinion research is currently conducted either at university departments or at non-profit communication institutes; therefore, it can no longer serve as a quick and easily available means for gathering data considered important by policymakers. These private research institutes see themselves as providing a commercial service, unlike the early academic research community's self-perception as a partner in social policymaking, as was the case with the IASR and the HUJ Institute of Communication.

At present, only a few agencies perceive themselves as public service providers. For example, the Second Authority for Television and Radio $^{3}$ is compelled by law to finance research projects that develop media policies for public interest. The actual research conducted by this body is supervised by prominent academic figures. In the last decade, among other initiatives, the Second Authority has commissioned an ongoing

\footnotetext{
${ }^{2}$ The exception to this rule was the Dahaf Agency, directed by Mina Zemach, which was a commercial enterprise from its inception in 1980. However, it is important to note that Mina Zemach maintained a close professional connection with both the HUJ Institute of Communication and the IASR.

3 See http://www.rashut2.org.il/english_about_loby.asp.
} 
research project to map out the social and ethnic diversity of Israelis appearing on prime-time television programs; the representation of people with special needs on television $(2003,2005,2011)$; the reality within "reality TV shows" (2007); parliamentary debates in the Israeli Knesset on media regulation (2007); newspaper readership among religious women (2007); and body image as represented on Israeli commercial television (2007). Many of these projects' recommendations are actually applied by this commercial TV channel when designing individual programs and general broadcasting policy.

Another more recent trend evident regarding the institutional-contextual dimension is increasing gaps and conflicts faced by the communication institutions of higher learning, both with political institutions and with media industry institutions. On the political front, beginning in 1977, exacerbated following Prime Minister Yitzhak Rabin's political assassination in 1995, and continuing up to the present, the dominant ideology in Israel has shifted from a leftwing secular orientation to rightwing neo-liberalism supported by Israel's religious and ultra-religious political parties. Furthermore, profound changes in the structure of the elite strata in Israeli society-shifting from relatively small elite networks of Labor Party-affiliated Ashkenazi Jews to larger and "messier" elite networks of orthdox Ashkenazi Jews, religious Sephardic Jews, Russian immigrant Jews, intellectual Israeli Arabs, and post-Labor secular Jews - did not occur in Israel's universities (Kimmerling, 2004). Most university and college faculty members are still leftwing, secular, and of Ashkenazi origin. Inasmuch as many faculty members in higher education institutions tend to lean more toward a leftwing worldview and political affinity, recent years have witnessed a growing distrust and even hostility between the political system and the system of higher learning, particularly in the social science departments (First \& Adoni, 2013). ${ }^{4}$ In the larger national context, schools/departments of communication are also frequently accused of at least partial responsibility for the antagonism characterizing contemporary interrelations between mass media and political institutions in Israel. University/college institutions are often charged with educating overly critical journalists who create "hostile media" that sometimes may contradict Israel's national interests (some say “nationalistic" interests) (Ram, 1994; Yoran, 2010).

The relationship between the media industry and academic research in communication is another example of alienation. Our recent findings (First \& Adoni, 2013) indicate that, when hiring professional personnel, media organizations do not give priority to candidates with a degree in communication, claiming that most of their academic studies are irrelevant for professional work in the industry. Furthermore, when planning their future policies, such media institutions do not often commission communication professors as consultants or committee members.

Moreover, into this broader context, we must also incorporate the rapid global development of various new media technologies like the Internet and cellular phones, which have penetrated every domain of quotidian life and thereby changed patterns of interaction between various social institutions (Castells, 1996; Nimrod, Nossek \& Adoni, 2015; Thompson, 2011). Consequently, in the last two decades, institutions of higher learning as well as the social research institutes charged with applied communication research have been challenged by the growing interdependence between profit-oriented organizations and the media industry—another factor that estranges the profit-driven media world from the academic world of the communication discipline.

\footnotetext{
${ }^{4}$ For instance, the Board of University Heads appealed to Israel's Supreme Court of Justice against the Government of Israel's recognition of Ariel College as a university (September 9, 2012), as a protest against the institution's location in the West Bank. Another example was when Ben-Gurion University's ostensibly leftwing Department of Communication and Politics was threatened with closure by a government committee (Council for Higher Education) in 2012.
} 
In sum, the contemporary alienated institutional-contextual picture in Israel today is a far cry from the earlier symbiotic interdependence shared by politicians, academics, and media leaders.

\section{The Institutional-In-Field Dimension: From Monopoly to Competition}

The second dimension of our interactive model focuses on science, including the communication discipline, as a social system and examines the power relations, division of resources, forms of competition, and patterns of recognition at play within the scientific community. Hagstrom (1965) argued that knowledge is a gift, in exchange for which scientists receive recognition from colleagues and peers. He claimed that deviance from normative scientific behavior, which often can be innovative, results from competition for collegial recognition. This conception of the scientific community as a social system has much in common with Bourdieu's (1993) concept of the symbolic field in general and the scientific field in particular. The scientific field is a relatively autonomous sphere that develops in accordance with its own laws, which steer and determine the interactions between individuals and social groups acting from their particularistic positions within this system. Above all, it is a system of power relations in which the legitimacy of participants' work is judged by their peers and competitors, and the sought-after reward is of a symbolic nature, such as a dominant position and authority in the field (Bourdieu, 1993). Our own analysis also refers to the structural-organizational aspects of academic institutions, the role of which is to produce and refine knowledge, transfer it to younger generations, and, if possible, apply it to solving practical problems of "field-level dynamic" (Bastedo, 2012; Clark, 1983) or, in our terms, institutional-in-field changes in various organizations of higher education.

In our earlier research on the development of the communication discipline in Israel (Adoni \& First, 2006), in examining the in-field-institutional dimension we described and documented the growth of the dominant institution in history of communication teaching and research in Israel, the Institute of Communication at the HUJ Social Science Faculty, from its establishment in 1966 and over the following decades. The organizational monopoly and intellectual hegemony of this Institute of Communication (which in the 1990s evolved into the Department of Communication and Journalism - the HUJ-DCJ) was absolute until the end of the 1980s. For example, in the 1970s, the Israel Council for Higher Education opposed opening a communication program at Tel Aviv University, claiming that the HUJ was providing all the needs of the market in this new field.

Since the late 1980s, following a shift toward neo-liberal free competition in Israel, communication departments and schools have been established in 14 academic institutions of higher learning in addition to that at HUJ. These included departments/schools at five other universities (Tel Aviv, Haifa, Ben-Gurion, Bar Ilan, and Open University) as well as at eight private and public colleges throughout the country. These new departments/schools, initially established and operated almost exclusively by faculty who were formerly students or faculty at the HUJ department, were substantially influenced by that originally monopolistic department in terms of organization, teaching curricula, and research interests. Furthermore, while each of these newer departments has its own independent institutional affiliation, they all maintain an ongoing relationship and continuous negotiations with the HUJ department regarding organizational and intellectual issues in the field (First \& Adoni, 2013).

In terms of the in-field-institutional dimension (the power relations, divisions of resources, forms of competition and patterns of recognition) most of the departments adopted the HUJ or "Jerusalem model" of a school/department — as a single organizational unit inclusive of research subjects from diverse fields. Following 
the pluralistic intellectual trend in the field (see in-field-intellectual section below), these departments achieved an organizational "pluralistic compromise" that allows differing research approaches to coexist without separating them into different departments, as has occurred in some universities in the USA.

As shown in Table 2, currently many of the faculty members in Israeli communication schools/departments are doctoral graduates of the HUJ-DCJ, which was and still is heavily oriented toward American scholarship. Most faculty members in Israel as of 2011 actually obtained their PhD in the USA, and a small minority graduated in Britain or France. Despite the large numbers of immigrants who arrived in Israel from the former Soviet Union since the early 1990s, their numbers in communication schools/departments are quite limited, and the number of Arabs is quite negligible.

Through the last decade, in an attempt to satisfy students' demands and to develop unique features, many of these schools/departments expanded the professional journalism aspects of their curricula, incorporating professional experience components spanning all the major old and new media (First \& Adoni, 2013). The pioneers in this respect were the newly founded colleges, which responded to the popularity of radio among students by founding their own campus radio stations. In this special case, the pattern of influence was reversed when the HUJ-DCJ followed the private colleges' example and founded its own radio station. At present, most schools/departments of communication have their own radio station broadcasting on a special wave dedicated to educational broadcasts.

Table 2

Higher Learning Institutions Where Israeli Tenured Faculty Members in Communication Departments Obtained Their Doctorate

\begin{tabular}{|l|l|l|l|l|}
\hline $\begin{array}{l}\text { Hebrew University of } \\
\text { Jerusalem }\end{array}$ & Bar-Ilan University & $\begin{array}{l}\text { Other Israeli } \\
\text { universities }\end{array}$ & Universities in the USA & European universities \\
\hline 15 & 4 & 7 & $\begin{array}{l}23 \\
6 \text { at Annenberg, } \\
\text { Philadelphia })\end{array}$ & $\begin{array}{l}6 \\
(2 \text { in Britain; 3 in France; } 1 \text { in } \\
\text { Russia })\end{array}$ \\
\hline
\end{tabular}

Note. Source, 2011: Curriculum Vita of faculty members from the official publications of these Universities.

The case of campus radio illustrates the fact that the influence of the HUJ-DCJ is strong but not all-encompassing, as some new schools/departments are trying to develop and highlight their own unique merits. Various newly founded communication schools/departments aspire to construct their unique identity and to distinguish themselves from other organizations by developing their own "specializations". For example, the Netanya Academic College strongly focuses on qualitative cultural studies of journalism; the Herzliya Interdisciplinary Center boasts a strong group of "new media" researchers; and the HUJ-DCJ offers a political communications program in a joint project with the Department of Political Science. This growing diversity is developing without destroying the "pluralistic compromise" within each of the communication departments.

The status of professional journalistic studies in Israeli institutions of higher learning is rather peculiar. Due to the initial failure of Katz's attempt to integrate professional and academic studies, theory and research held highest status in communication studies at the early stages of the discipline's development. This contrasted with the development of the discipline in the USA, where schools of journalism preceded departments of communication. Our prior research analyzing the curricula of communication departments in various Israeli universities and colleges revealed that professional training has not attained equal status to more theoretically oriented studies. Repeated attempts to link theory and practice in the teaching process met with limited success, 
and the process of integrating journalistic studies into Israeli communication departments failed. Consequently, journalism studies hold a low academic status compared to communication studies. An additional weakness of journalistic curricula is the relatively limited professional practicum offered. All the existing communication programs include professional workshops and practicum in external media organizations, and some of the colleges even offer an expanded professional program. However, the greater part of the curricula still deals with theories and communication research, and courses on these subjects render higher credits. Furthermore, although the professional practicum is taught by the best professionals available, these faculty members have a secondary, temporary status compared to researchers, who are tenured faculty (First \& Adoni, 2007).

The main in-field-institutional change that has occurred in Israel during the last five years is the growing number of schools/departments that have obtained accreditation by the Council of Higher Education to offer graduate programs in communication. At present, the top five major universities (HUJ, Tel Aviv, Haifa, Ben-Gurion, and Bar Ilan) all offer programs for both MA and PhD degrees in communication studies. Recently, three new master's programs were recognized in communication schools at private colleges: Netanya Academic College, College of Management Academic Studies, and Herzliya Interdisciplinary Center. The accreditation of such programs by the Council of Higher Education is not easily obtained. It requires massive investments of money and other resources in new classrooms, library materials, and basic equipment as well as recruiting a substantial number of new faculty members (e.g., in a department of 10 tenured faculty members, adding five new members of varying academic ranks). Until recently, student demand for all the communication schools/departments was high, and the number of students increased steadily. These favorable economic circumstances allowed institutions to hire the required academic personnel and enabled the development of advanced degree programs. However, in the last two years (2013-2014), a marked downward trend was noted in registration rates, causing concern that this trend might erode the status of some of the existing communication departments, which have not yet reached the consolidation phase in terms of faculty numbers and student body size.

The existence of professional networking and the establishment of professional associations and societies is an important component in a disciplinary field's process of institutionalization (Eadie, 2013; Meyen, 2013). Accordingly, the continual growth in the membership of the Israel Communication Association ${ }^{5}$ indicates an impressive process of professional networking. Established in 1995 with a handful of members, this association counts over 200 members today, including faculty from all the communication schools and departments in Israel, as well as teachers of communication in high schools. Every year, the Israel Communication Association organizes a one-day conference, with high attendance and about 15 parallel sessions on different subjects. The association also publishes a Hebrew-language quarterly titled Misgarot Media ("Media Frames"). The great majority of Israel Communication Association members are also members in the International Communication Association, the International Association for Media and Communication Research, and other professional associations. They are quite active in these and other international forums, attending annual conferences regularly.

In conclusion, our findings demonstrate that regarding the institutional-in-field dimension in Israel, a profound shift occurred since the end of the 1980s. From a total, indisputable monopoly by the HUJ Institute of Communication, a constellation of various learning institutions emerged, both private and public, competing

\footnotetext{
${ }^{5}$ Israel Communication Association. Retrieved from http://isracom.org.il/?cmd=classes.
} 
among them for students, faculty, and scientific recognition.

\section{The Intellectual-In-Field Dimension: From Intellectual Hegemony to Limited Pluralism}

From its very beginnings and up until the present, the in-field-intellectual dimension of the communication discipline has been rooted in different areas of knowledge and has employed diverse research methods reflecting its interdisciplinary nature and lack of clear boundaries. As a result, researchers from different disciplines around the globe continue to contribute to communication research while challenging conventions and proposing alternative paradigms. ${ }^{6}$ Delineating the field's boundaries, defining its central paradigms, and accumulating a cohesive body of knowledge have constantly posed a challenge for communication scholars, culminating in voluminous literature on the subject. In contrast to recent attempts to find a single new, comprehensive paradigm (Lang, 2013), we tend to agree with McQuail (2013, p. 216), who recommended dealing separately "with a few main clusters of issues ... that have received most attention" in communication research. Consequently, in our analysis of the in-field-intellectual dimension in the Israeli case, we intentionally avoided the issue of a dominant paradigm, and instead we examined the main clusters of topics of scholarly interest among Israeli communication scholars.

As mentioned above, in the early phases of the communication field in Israel, the functional approach to the study of mass communication and the quantitative research orientation dominated. This situation developed due to "personal transfer" or "academic drift" (Katz, 1997) phenomena, involving the transfer of knowledge and capabilities via personal initiative from one organized institutional framework to a new one. Inasmuch as specific individuals undertake intellectual initiatives, they do not necessarily represent the variety of initiatives in the field; nevertheless, these individual researchers can become the founders of a new field outside their original organizations (Katz, 1997). This happened in the cases of Elihu Katz and Louis Guttman, who both immigrated to Israel and personally transferred to Jerusalem two major aspects of the academic knowledge that had developed in prominent universities in the USA: namely, the functional and empirical approach to mass communication (Katz \& Lazarsfeld, 1955; Blumler \& Katz, 1974) and applied social research (Shye, 1978). Another example of this personal transfer phenomenon is the development of the communication field in China, which was initiated by Wilbur Schramm who activated the process of academic drift from American academics to Chinese institutions of higher learning (Fei \& Kuo, 2013).

In the 1980s, Israeli scholars, like their American colleagues, were influenced by new critical approaches to communication such as the Frankfurt school, cultural studies, linguistics, and feminism (Adoni and First, 2006). One of the most important developments characterizing the in-field-intellectual dimension in Israel took place when two prominent scholars of the Hebrew language, the late Shoshana Blum-Kulka and the late Raphael Nir, who previously held positions in the School of Applied Linguistics, were invited by Elihu Katz and the late Brenda Danet to join the HUJ Institute of Communication (see Hebrew University of Jerusalem, 1980-81). New research topics and methods were immediately included in the curriculum, such as discourse studies, linguistics, translation, rhetoric, and the language of the Israeli media. This was not an easy transition, opposed by about half of the faculty. They argued that the Institute of Communication as a part of the HUJ Social Science Faculty must maintain its central functional orientation based on quantitative methods of

\footnotetext{
${ }^{6}$ This diversity was evident in the interviews we conducted with Israeli researchers, none of whom offered us a comprehensive definition of the field. Instead, each scholar emphasized a different domain of knowledge that in his/her view is central to communication research.
} 
research. Nevertheless, after an exchange of quite bitter arguments from the both sides, the communication discipline's boundaries in the Jerusalem department were crossed and forever changed. At a more profound level, subjects that were traditionally part of the humanities became legitimized, thereby enabling the growth of a young generation of ommunication scholars who asked somewhat different questions and used different methodologies.

Thus, during the 1980s, the functionalist hegemony of the HUJ Institute of Communication eroded further, as the curriculum expanded to include courses on different genres of popular culture. In that period, Katz became interested in study of popular texts, the study of which required a qualitative methodology. The overall trend moved toward the humanities and toward increasing implementation of qualitative empirical methods.

These developments in the American-oriented Israeli communication field essentially mirrored the well-known 1993 special issue of the Journal of Communication, where leading researchers discussed the field's future and finally reached a "comfortable acceptance of theoretical pluralism" (Levy \& Gurevitch, 1993, p. 4). Gradually increasing coexistence of approaches was slowly removing the sting from the strident debates between differing paradigms in the field. This trend toward intellectual pluralistic compromise was reflected not only in the variety of research perspectives presented in the 1993 special issue but also in more recent attempts to define the canonical literature of the field (Katz, Peters, Liebes, \& Orloff, 2003). The new boundaries of this field of scholarship, as developed in Israel since the end of 1980s, encompassed both functional-quantitative studies and a variety of discourse and cultural studies based on qualitative research.

Our examination of current Israeli researchers' publications ${ }^{7}$ revealed the following dominant research interests of Israeli scholars: (1) political communication, including public opinion, regulation and law, the Israeli-Arab conflict, public diplomacy, terror, media frames, reality construction, etc.; (2) popular culture, including cultural diversity, communication and leisure, collective memory, representation, reality shows, advertising, media and children, media and minorities, etc.; (3) history of communication; (4) public relations; (5) ethnography of communication; (6) new media; (7) visual communication; (8) sociolinguistics and conversational formats; and (9) cinema. Scholars explored these issues using a mixture of research methods including the analysis of production, content, and audience. Analysis of media content, media use, and media effects on audiences are the prevalent research interests, whereas the study of organizational aspects of media is less common. Regarding research on journalism in Israel, we share the general conclusions of Meyers (2004) and Zelizer (1998), who asserted that the basic communication textbooks rarely include systematic research conducted over extended time periods, dealing with journalistic norms and values.

Israeli scholars' publication lists from 2012 indicate that the most salient topics of research in recent years deal with new media. In fact, in the wake of the ascent of new media, communication researchers needed to revisit and rephrase classic questions regarding media organizations, contents, and audiences. The late Brenda Danet from HUJ was pioneering in the international communication field by already grasping the importance of the Web in the early 1990s and starting to study it systematically.

Notably, despite the new legitimacy of diversified theoretical approaches, the ideological framework for communication research in Israel has remained largely Zionist, with more radically critical approaches (like neo-Marxist and post-Zionist) remaining marginal. Today, although the communication discipline is no longer a "mobilized academy" as in the 1960s and the 1970s, most research topics in the communication discipline

\footnotetext{
7 Our source for these data was the publication lists of all tenured-track communication faculty members in all the universities in Israel as of 2012.
} 
continue to address central Israeli issues without taking a radical critical stance toward them.

Feminist research remains limited in scope and is still undertaken mainly, though not exclusively, by women scholars. Moreover, due to the lack of neo-Marxist and post-colonial research traditions, the Israeli communication scene completely lacks research on the political economy of communication and its impact on media and popular culture.

Works by Israeli scholars appear in the most prestigious publications (according to their impact factor ranking), which are mostly American. Although there are some excellent professional journals published in Israel, publishing in Hebrew holds a relatively low status in Israeli academic institutions' tenure procedures and is not considered equal to English language publications. The rationale of this policy is that the Israeli community of researchers is relatively small and, consequently, cannot ensure objective and valid peer evaluation.

In sum, although a variety of research topics is evident among scholars coming from a similar intellectual background, the overall feeling is one of strong orientation toward USA scholarship and long-lasting frequent collaboration with American institutions of higher learning. Across the board in all of the communication schools/departments, despite existing collaborations with Western European institutions, Israeli scholars continue to perceive American communication scholarship to be the "universal" essence of the discipline's academia (Billig, 1995).

\section{The Intellectual-Contextual Dimension: From Inferiority to Equality?}

The intellectual-contextual dimension of the communication field in Israel, much as in the USA, is related to communication scholars' wide-ranging diversity in their stance on cognate disciplines both from the social sciences and the humanities. Stemming from various cognate disciplines adopted by the founders of the field (Schramm, 1997), this newcomer to the disciplinary family of social sciences was originally received by the veteran disciplines with a reserved and even patronizing attitude. Pooley and Katz (2008) surveyed various disciplinary links between sociology and communication and demonstrated that scholars who were interested in the communication discipline in its early stages, such as Robert Merton and Robert Park, eventually returned to their original disciplines and lost interest in the burgeoning communication discipline.

In the case of the Israeli field's early stages, according to Elihu Katz (interview, August 2002), the Department of Sociology at the HUJ, which hired him personally, was not especially interested in developing the communication field within the department, a phenomenon familiar to Katz from the University of Chicago. In our earlier research (Adoni \& First, 2006, First \& Adoni, 2007), we noted that for many years the focus of Israeli sociology and political science had been on classic sociological questions concerning class, the generation gap, ethnicity, immigration, political identification, and national identity, and later also on gender, religiosity, and the Israel-Palestinian conflict. However, interest in and study of communication processes related to all these issues had been conspicuously missing.

It is evident that since the communication field's inception in Israel in the 1960s at HUJ, the Institute of Communication's relations with other HUJ university departments could be characterized as a mix of attraction and rejection. Attraction to the communication field in Israel stemmed primarily from the recognition of its rapid development, along with demands by professionals and local market forces. Rejection resulted from the more well-established disciplines' reservations about a new field of knowledge with fluid intellectual boundaries, on the one hand, and a professional journalistic orientation, on the other hand. 
HUJ's Institute of Communication was founded in 1966 as a part of the Social Sciences Faculty. In the humanities departments, even those who recognized the potential linkages between communication and diverse humanities fields like literature and linguistics initially looked askance at the notion of convergence with a field having such a distinctly social science orientation. In the social sciences departments at HUJ, another problematic in-field-intellectual issue emerged from the close and fruitful early collaboration described above between HUJ's Institute of Communication and Louis Guttman's IASR. This collaboration brought to the surface questions regarding the status of applied social research as a part of the new communication discipline. In the social science departments at HUJ, there was general consensus that basic research enriches the communication field by accumulating theory and knowledge, thus helping solidify the field's disciplinary identity and prestige. In contrast, applied social research was not always perceived as scientifically rigorous and therefore was sometimes seen as diminishing the status of communication as a scientific discipline, even though such research often held significant social implications for cultural and social policies and even served as a basis for important scientific contributions.

It should be noted that when the HUJ Institute of Communication was founded in 1966, all the other departments in the social sciences faculty had already been well established. As the latest newcomers, communication faculty members had to struggle for their field's recognition as an autonomous field of inquiry. These pioneers paved the path for other communication schools/departments founded in Israel during the 1990s and later. However, each new communication school/department continued to face a similar struggle to achieve equal status among existing faculty departments at each university/college. The reason for this is probably anchored in the communication field's fundamentally interdisciplinary features, its links to the journalistic profession, and its ties to applied social research.

Another reason for the suspicion and opposition encountered by the communication discipline in Israel during the last decade, may stem from the fact that post-Zionist trends did not generally typify the new schools/departments of communication. This contrasted to departments of sociology and political sciences in some academic institutions, where scholars developed a strong critical stance towards the Zionist hegemony during the 1990s (often termed post-Zionistic theories).

Nevertheless, in our opinion, during the 1990s, the academic status of communication schools/departments substantially improved in the eyes of other departments because of the high demand for communications studies by potential students (First \& Adoni, 2013). In all Israeli universities and colleges, communication departments were recognized as an asset and were encouraged by the management teams who grasped their economic potential. This demand can be seen as linked to the profound changes in media and technology that transpired globally over recent decades. The penetration of new media into all domains of private and public life and their adoption by millions of people around the world have challenged scholars from both communication and other disciplines to ask new questions and to revisit old ones concerning communication processes in the rapidly developing contemporary media environment. To put it more bluntly, social scientists could no longer ignore the social, political, and cultural significance of these processes and began attempting to integrate them into their own research.

In the long run, one implication of the proliferation of new media may be a renaissance of interdisciplinary cooperation between communication, sociology, social psychology, and political science. One example of this trend for collaboration between communication scientists and their cognate disciplines is the aforementioned new political communications program offered at both the HUJ and the Herzliya Interdisciplinary Center, as a 
joint project of their respective communication and political science departments. We would like to emphasize that, in both of these institutions, the political science departments initiated these joint projects in the hopes of increasing their student enrollment numbers by adding the appeal of the communication discipline.

\section{Some Thoughts on the Dynamic Interaction Model and Future Research}

In the present article, we applied our interactive conceptual model to our prior historical analysis of the long-term transformations that occurred in Israel's communication field since its inception in the 1960s, as well as to the recent short-term developments in the field in the last decade. Our main findings, according to the interactive model, point towards four main changes in the communication field in Israel. First, regarding the institutional-contextual dimension in the Israeli case, our findings indicated that the communication discipline experienced a significant transition from symbiotic integration between institutions of higher learning and the larger political and ideological context during the early years of this fledgling nation's development, to increasing alienation between them in recent years. Second, from the perspective of the in-field-institutional dimension, we pinpointed a prominent shift, from full institutional monopoly of the Israeli communication field by the pioneering American-oriented HUJ Institute of Communication (later the HUJ-DCJ) to a multiplicity of accredited schools/departments of communication around the country and growing competition among them. Third, regarding the in-field-intellectual dimension, we pinpointed a change that occurred in Israel from intellectual hegemony to limited intellectual diversity, often termed as "limited pluralism". And fourth, from the point of view of the intellectual-contextual dimension, our analysis uncovered a shift from the communication field's inferior status among its cognate social science disciplines to a certain improvement in its status, mostly due to the popularity of communication studies in the 1990s and first decade of the present century.

Overall, this analysis suggested that as postulated in our interactive model, changes in each of the four explored dimensions interacted with developments in all the other dimensions. For example, institutional-contextual transformations-in Israeli politics and economics as result of neo-liberal shifts - created conditions for opening and privatizing the educational system and consequently caused the major long-term institutional-in-field change experienced historically in the Israeli communications field: the end of the HUJ monopoly and the opening of communication schools/departments at other universities as well as at both private and public academic colleges all over the country. As a consequence of these circumstances, each academic institution has aspired to develop its own idiosyncratic intellectual character, encouraging greater diversity in the in-field-intellectual dimension, through different emphases on specific topics in these departments' syllabuses and in faculty domains of research. This trend, which started in the late 1990s, is still strongly felt up to the present day. We suggest that this shift also strongly affected the applied social research connected with the in-field-institutional dimension of the communication field. As mentioned above, instead of a dominant IASR which was interested in contributing to the public policy regarding communication and culture, during the late 1980s a burgeoning increase of private, profit-oriented research institutes began.

During the last two decades, the in-field-intellectual dimension of the communications field witnessed a weakening of the functional, quantitative research approach and opened up to more critical approaches and to research topics dealing with popular culture, politics of identities, new media, and their audiences. In our opinion, these changes characterizing the intellectual-in-field dimension are at least partially the result of alienation between societal institutions and academic researchers, who are no longer frequently asked to 
provide a basis for political and social policies. This diversifying trend, which continues up to the present, occurs alongside ongoing negotiations about the field's boundaries, generating a varied, growing body of knowledge. The blurry margins have a certain advantage for the intellectual-contextual dimension, as they create opportunities for encounters with the humanities, social sciences, and technology.

Indeed, through the communication field's interactions with a growing number of cognate disciplines, intellectual-in-field changes have manifested as diversified communications perspectives. However, a recognizable continuity in the research questions asked and the subjects studied can easily be noted; these have continued to focus most often on media institutions, communication processes, media contents, and their effects on different audiences. It could be argued that this variegated scientific output is not an artificial and arbitrary compromise but, rather, an ontological pluralism that enables different fields of knowledge to enrich communication studies (Beniger, 1993; Peters, 1993; Shepherd, 1993). Their common feature is a focus on topics relevant to the field rather than on defining its boundaries or its dominant paradigm. Possibly as a result of the Israeli field's historical bonds with the hegemonic ideology and governmental bodies in its early stages (institutional-contextual dimension), during the last 20 years communication scholars, unlike their counterparts in cognate disciplines (intellectual-contextual dimension), have not produced a body of post-Zionist or post-colonial communication research. In future research, we recommend further exploration of the patterns of interaction between the four dimensions and if possible hypotheses on the causal directions and extents of influence among different dimensions.

Our last comment refers to the aforementioned need for cross-cultural or cross-national study of the communication discipline, which has been rather neglected and limited in the literature. As mentioned above, we recommend that the interactive conceptual model developed in our study can serve as a common conceptual and operational denominator ensuring a non-culture-bound analysis and enabling the systematic study of all four dimensions of the communication discipline in different societies. However, when applying this model to a specific case study, we recommend complementing the interactive conceptual analysis with an empirical historical methodology. In the Israeli case, we felt that the complementary historical approach was necessary to prevent the risk of losing the cultural specificity and richness of the phenomena explored and to provide the essential historical information dealing with idiosyncratic aspects of Israeli culture and society (Ben David, 1991).

We strongly suggest that the future research of the communication discipline utilize these dual, complementary strategies: analysis based on the conceptual four-dimensional interactive model, complemented with the idiosyncratic and unique story of each society. In fact this is essential for cross-cultural research on any subject (Adoni,1989; Adoni, Caspi, \& Cohen, 1991; Cohen, Adoni, \& Bantz, 1990) and in particular for research on the development of the communication field.

\section{References}

Adoni, H. (1989). Supplementary strategies in comparative news research. American Behavioral Scientist, 33, $234-237$.

Adoni, H., \& First, A. (2006). Structural dilemmas in the consolidation of communication research and reaching: The case of the Department of Communication at Hebrew University of Jerusalem. Jerusalem: Magnes Hebrew University Press.

Adoni, H., Caspi, D., \& Cohen, A. (1991). Media, minorities and hybrid identities: The Arab and Russian communities in Israel. Cresskill, NJ: Hampton Press.

Alexander, J. (1998). Neofunctionalism. Beverly Hills, CA: Sage.

Bastedo, N. M. (2012). The organization of higher education: Managing colleges for a new era. Baltimore, MD: Johns Hopkins 
University Press.

Ben David, J. (1991). Scientific growth. Berkeley: University of California Press.

Beniger, R. J. (1993). Communication: Embrace the subject, not the field. Journal of Communication, 43(3), 18-26.

Billig, M. (1995). Banal nationalism. London: Sage.

Blumler, J., \& Katz, E. (1974). The uses of mass communication. London: Sage.

Bourdieu, P. (1993). The field of cultural production. London: Polity Press.

Castells, M. (1996). The rise of the network society. Oxford: Blackwell.

Clark, R. B. (1983). The higher education system: Academic organization in cross-national perspective. Berkeley: University of California Press.

Cohen, A. A., Adoni, H., \& Bantz, C. (1990). Social conflict and television news. London: Sage.

Crane, D. (1994). Introduction: The challenge of the sociology of culture to sociology as a discipline. In D. Crane (Ed.), The sociology of culture: Emerging theoretical perspectives (pp. 1-20). Cambridge, MA: Blackwell.

Eadie, W. F. (2013). Communication societies in the U.S. and the transition from field to discipline. Proceedings from the International Communication Association Preconference of New Histories of Communication Study, London.

Eisenstadt, S. N. (1989). The transformation of Israeli society. Jerusalem: Magnes Hebrew University Press.

Fei J., \& Kuo, H. (2013). Understanding Chinese communication studies from the perspective of neo-knowledge production. Proceedings from the International Communication Association Pre-Conference on New Histories of Communication Study, London.

First A., \& Adoni, H. (2013). Communication field in Israel: From growth to consolidation, from uniformity to diversity. Proceedings from the International Communication Association Pre-Conference on New Histories of Communication Study.

First, A., \& Adoni, H. (2007). The never-ending story: Coping with structural dilemmas of the communication field. Mass Communication and Society, 10(3), 251-273.

Foucault, M. (1969/2002). The archaeology of knowledge. London: Routledge.

Freudenthal, G. (1991). General introduction: Joseph Ben David, an outline of his life and work. In J. Ben David (Ed.), Scientific growth. Berkeley: University of California Press.

Gratch, H. (1973). Twenty-five years of social research in Israel. Jerusalem: Academic Press.

Hagstrom, W. (1965). The scientific community. New York: Basic Books.

Hebrew University of Jerusalem. (1980-81). University yearbook. Jerusalem: Hebrew University Press.

Katz, E., \& Lazarsfeld, P. (1955). Personal influence. New York: Free Press.

Katz, E., Peters, J. D., Liebes, T., \& Orloff, A. (2003). Canonic texts in media research: Are there any? Should there be? How about these? Cambridge, UK: Polity Press.

Katz, S. (1997). "Pure science" in a national university: The Einstein Institute of Mathematics and other institutes at the Hebrew University during its formative years. In S. Katz, \& D. Heyd (Eds.), The history of the Hebrew University of Jerusalem (pp. 397-457). Jerusalem: Magnes Hebrew University Press.

Katz, S., \& Hed, D. (1997). The history of the Hebrew University of Jerusalem. Jerusalem: Magnes Hebrew University Press.

Kimmerling, B. (2004). Immigrants, settlers, natives: The Israeli state and society between cultural pluralism and cultural wars. Tel Aviv: Am Oved.

Lang, A. (2013). Discipline in crisis? The shifting paradigm of mass communication research. Communication Theory, 23(1), $10-24$.

Levy, R. M., \& Gurevitch, M. (1993). Editorial. Journal of Communication, 43(3), 3-5.

Mannheim, K. (1952). Essays on the sociology of knowledge. London: Routledge \& Kegan Paul.

McQuail, D. (2013). Reflections on paradigm change in communication theory and research. International Journal of Communication, 7, 216-229.

Merton, R. (1957). Social theory and social structure. New York: Free Press.

Meyen, M. (2013). IAMCR on the east-west battlefield. Proceedings from the International Communication Association Pre-Conference on New Histories of Communication Study, London.

Meyers, O. (2004). A communication problem. Proceedings from the Coverage as a Narrative Conference in honor of Yitzchak Roeh, Hebrew University, Jerusalem.

Nimrod, G., Nossek, H., \& Adoni, H. (2015). The Internet as cultural form. The International Journal of Communication, 9, $321-341$.

Peters, J. D. (1993). Genealogical notes on “the field”. Journal of Communication, 43(4), 132-140. 
Pooley, D. J., \& Katz, E. (2008). Further notes on why American sociology abandoned mass communication research. Journal of Communication, 58(4), 767-786.

Pooley, D. J., \& Park, W. D. (2013). Communication research. In P. Simonson, J. Peck, R. T. Craig, \& J. P. Jackson (Eds.), The hhandbook of communication history (pp. 76-93). New York: Routledge.

Ram, U. (1994). Israeli society: Critical perspectives. Tel Aviv: Breirot.

Schramm, W. (1997). The beginnings of communication in America. Thousand Oaks, CA: Sage.

Shepherd, J. G. (1993). Building a discipline of communication. Journal of Communication, 43(3), 83-92.

Shye, S. (1978). Theory construction and data analysis in the behavioral sciences. San Francisco: Jossey Bass.

Simonson, P., \& Peters, D. J. (2008). Communication and media studies history to 1968. In W. Donsbach (Ed.), International encyclopedia of communication (pp.764-771). Malden, MA: Blackwell.

Simonson, P., Peck, J., Craig, T. R., \& Jackson, J. P. (2013). The handbook of communication history. New York: Routledge.

Thompson, J. B. (2011). The media and modernity. Cambridge, UK: Polity Press/Blackwell.

Yoran, N. (2010). Television as a medium is the certainty of shock. In D. Arieli-Horowitz, \& D. Sering (Eds.), Fear of death:

Terror and its manifestations in popular art and culture. Jerusalem: Magnes Hebrew University Press.

Zelizer, B. (1998). The failed adoption of journalism study. Press/Politics, 3(1), 113-121. 